\title{
Análise Comparativa do Engajamento de Universidades Públicas em Sistemas Municipais de Cultura
}

\author{
José Ricardo Vitória ${ }^{1}$ \\ Mateus Cerqueira Anício Morais ${ }^{2}$ \\ Magnus Luiz Emmendoerfer ${ }^{3}$ \\ Nina Rosa da Silveira Cunha ${ }^{4}$
}

Comparative Analysis of Public Universities'engagement in Municipal Culture Systems

Análisis Comparativo de la Participación de las Universidades Públicas en Sistemas

Culturales Municipales

\section{Resumo}

Para que os Sistemas Municipais de Cultura (SMCs) alcancem seus objetivos é necessário que todos os atores e instituições participantes de seus processos de elaboração e implementação estejam efetivamente envolvidos, buscando canais que viabilizem diálogos duradouros. Nesse contexto, as universidades públicas tornam-se importantes atores sociais. Por meio de uma abordagem qualitativa de estudos de caso em perspectiva comparada, objetivou-se analisar o engajamento de universidades públicas em processos de implementação de Sistemas Municipais de Cultura em quatro cidades do estado de Minas Gerais (Viçosa, Ouro Preto, Cataguases e Ponte Nova). Os resultados apontam que, apesar de seu potencial de atuação sobre o desenvolvimento da cultura, as universidades não estão cumprindo seu papel junto aos sistemas municipais estudados.

Palavras-chave: Política pública; Extensão universitária; Sistema Municipal de Cultura.

1 Doutor, Mestre e Bacharel em Administração pela Universidade Federal de Viçosa (UFV). Membro do grupo de pesquisa Gestão e Desenvolvimento de Territórios Criativos (GDTeC) do Programa de Pós-Graduação em Administração Pública da UFV. E-mail: josericardovitoria@yahoo.com

2 Doutorando e Mestre em Administração pela Universidade Federal de Viçosa (PPGADM/UFV). Bacharel em Economia pela UFV. E-mail: mateuscamorais@gmail.com

3 Doutor em Ciências Humanas: Sociologia e Políticas, Universidade Federal de Minas Gerais (UFMG). Professor Associado, Programa de Pós-Graduação em Administração Pública, Universidade Federal de Viçosa (UFV). E-mail: magnus@ufv.br

4 Doutora em Economia Aplicada pela Universidade Federal de Viçosa (UFV). Professora Titular do Departamento de Administração e Contabilidade (DAD) e do Programa de Pós-Graduação em Administração Pública (PPGADM/UFV). E-mail: ninarosaufv@gmail.com

Agradecimentos: ao apoio da Coordenação de Aperfeiçoamento de Pessoal de Nível Superior - Brasil (CAPES) - Código de Financiamento 001. 
Abstract

For Municipal Systems of Culture (MSC) to reach their goals, the coordination between each actor and institution participating in this formulation and implementation process is necessary, aiming for the establishment of permanent dialogs. In this context, public universities are important social actors. Based on a qualitative approach, we perform a comparison of case studies to analyze public universities' engagement in the implementation process of Municipal Systems of Culture (MSC) in four cities in the Brazilian State of Minas Gerais (Viçosa, Ouro Preto, Cataguases e Ponte Nova). The results indicate that despite its potential to improve cultural development, Public Universities are not carrying out their expected role in the studied Municipal Systems of Culture.

Keywords: Public Policy; University extension; Municipal Systems of Culture.

\section{Resumen}

Para que los Sistemas Municipales de Cultura (SMC) alcancen sus objetivos, es necesario que todos los actores e instituciones que participan en sus procesos de elaboración e implementación estén efectivamente involucrados, buscando canales que hacen posibles diálogos duraderos. En este contexto, las universidades públicas se convierten en importantes actores sociales. A través de un enfoque cualitativo de estudios de casos en una perspectiva comparativa, el objetivo de este estudio fue analizar la participación de las universidades públicas en los procesos de implementación de Sistemas Municipales de Cultura en cuatro ciudades del estado de Minas Gerais (Viçosa, Ouro Preto, Cataguases e Ponte Nova). Los resultados muestran que, a pesar de su potencial para actuar en el desarrollo de la cultura, las universidades no están cumpliendo su papel en los sistemas municipales estudiados.

Palabras clave: Política Pública; Extensión universitaria; Sistemas Municipales de Cultura. 


\title{
Introdução
}

\begin{abstract}
Com base em uma nova visão das políticas públicas de cultura, fundamentada na Proposta de Emenda Constitucional (PEC) 34/2012, foi instituído o Sistema Nacional de Cultura (SNC) $)^{5}$, considerado na literatura como um marco histórico da democracia brasileira para o setor cultural (CUNHA FILHO, 2010). O SNC foi proposto para integrar a sociedade civil e os três níveis da federação de forma democrática, com base em um conceito sistêmico, orientado por um Plano Nacional de Cultura (BRASIL, 2020b).
\end{abstract}

Nessa conjuntura, cada ente federativo passou a ter um importante papel na formação do SNC (VITÓRIA; EMMENDOERFER, 2015), gerando diferentes expectativas para os envolvidos no campo da cultura, visto que o sistema tem por objetivo a descentralização das políticas culturais (MARTINS et al., 2016). Assim, almejou-se, com essa política, que o Sistema Municipal de Cultura (SMC) integrasse os municípios aos sistemas dos estados a que pertencem, bem como ao da União, com a finalidade de promover a partilha das responsabilidades comuns, para o desenvolvimento das culturas locais e regionais (PEIXE, 2013).

A efetividade das propostas que envolvem os SMCs e os objetivos pactuados na adesão ao SNC se desdobram na necessidade de envolvimento dos diversos atores e instituições presentes nesses sistemas. Estes, por sua vez, tendem a se concretizar por meio de "canais que viabilizem o diálogo duradouro entre indivíduos e coletividades criadoras, organizações, movimentos sociais e grupos culturais, empresas e empreendedores que atuam na área cultural, usuários e consumidores e os cidadãos em geral” (BRASIL, 2008, p. 12).

Nesse contexto, ressalta-se o potencial das universidades públicas para desempenhar significativos papéis como catalizadoras do desenvolvimento, visto sua importância na economia, na política e, principalmente, nas culturas em que estão inseridas (KAWASAKI, 1997). Em termos gerais, durante

\footnotetext{
5 Descrito no artigo 216-A da Constituição Federal Brasileira (BRASIL, 1988).
} 
séculos, as universidades têm se mostrado como redutos da produção e preservação da cultura, seja pela formação de artistas, pela criação de espaços artísticos, bem como pelo estudo e conservação das artes (CHATTERTON, 2000; GILMORE; COMUNIAN, 2016).

No contexto brasileiro, o Plano Nacional de Educação (PNE 2014-2024), estabelecido pela Lei 13.005 de 25 de junho de 2014, prevê que programas e projetos de extensão universitária tenham suas ações orientadas, prioritariamente, para áreas de grande pertinência social, como a cultura (BRASIL, 2014). Assim, as universidades públicas, orientadas pelo princípio de indissociabilidade entre ensino, pesquisa e extensão, bem como pela responsabilidade em relação à transformação social, previstos nas Diretrizes para as Políticas de Extensão da Educação Superior Brasileira (BRASIL, 2018), mostram-se essenciais para o desenvolvimento, inclusive em termos culturais. Isso permite considerar a extensão universitária como um elemento indutor e promotor de ações em prol da cultura local e regional.

Esse papel da universidade ganha destaque principalmente quando se trata da contribuição desses atores para as políticas voltadas para o desenvolvimento econômico (ETZKOWITZ; LEYDESDORFF, 1999; ETZKOWITZ et al., 2000; OWEN-SMITTH; POWELL, 2003; WOLFE, 2005). Quando se trata de questões que envolvem o papel das universidades no contexto do desenvolvimento cultural, as produções científicas tendem a ser limitadas, apesar do potencial dessas instituições para a efetivação de políticas públicas nesse âmbito.

Com base neste contexto, questiona-se no presente artigo se as universidades públicas brasileiras têm consolidado seu potencial de transformação da realidade no âmbito cultural, por meio do envolvimento nos SMCs, das regiões onde se inserem. Nesse sentido, objetiva-se analisar o engajamento dessas universidades no processo de implementação desses sistemas.

Destarte, buscou-se comparar quatro sistemas municipais de cultura de cidades do estado de Minas Gerais. Dos casos estudados, dois envolvem municí- 
pios que possuem universidades públicas em seus territórios (Viçosa e Ouro Preto); os outros dois (Ponte Nova e Cataguases) referem-se a municípios não contemplados com a presença de instituições dessa natureza em seus limites territoriais.

Como pressuposto, acredita-se que a presença das universidades públicas na constituição dos SMCs tende a gerar sistemas mais robustos e avançados, em comparação com realidades onde não haja a presença efetiva dessas instituições de ensino. Espera-se que esse estudo contribua para a ampliação das discussões a respeito do papel delas em políticas de cultura no Brasil, além de oferecer evidências a respeito da implementação do SNC no âmbito local (BRASIL, 2020a).

\section{Papel das universidades na implementação de políticas públicas de cultura}

Há diversas noções e conceituações acerca de políticas públicas, com sentidos e funções variadas. Contudo, é comum entre elas a noção de que elas servem para amenizar ou solucionar um problema entendido como coletivamente relevante (FREY, 2009; LANE, 2000; SECCHI, 2013; SOUZA, 2006; TEIXEIRA, 2002).

De acordo com Teixeira (2002, p. 2), políticas públicas são “diretrizes, princípios norteadores do poder público, regras e procedimentos para as relações entre poder público e sociedade, mediações entre atores da sociedade e do Estado”. Assim, as políticas públicas, de maneira geral, envolvem aplicações de recursos públicos. Seus objetivos e diretrizes são especificados e orientados por documentos oriundos de seu processo de formulação. Contudo,

nem sempre [...] há compatibilidade entre as intervenções e declarações de vontade e as ações desenvolvidas [sendo preciso considerar] as omissões como formas de manifes- 
tação de políticas, pois representam opções e orientações dos que ocupam cargos. (TEIXEIRA, 2002, p. 2)

Existem tipologias e modelos criados para compreender o processo de elaboração das políticas públicas, dentre os quais se destaca o ciclo de políticas públicas (policy cycle). Este modelo "é um esquema de visualização e interpretação que organiza a vida de uma política pública em fases sequenciais e interdependentes” (SECCHI, 2013, p. 33). Essa forma de ilustração colabora para que os interessados - políticos, administradores, gestores e pesquisadores - tenham um referencial comparativo para distintos casos em análise.

As fases consideradas no ciclo de política pública podem variar entre os autores na literatura especializada, contudo é comum, nas diversas vertentes, as etapas de: (i) formulação; (ii) implementação; (iii) avaliação de políticas públicas (FREY, 2009; SECCHI, 2013; THOMAS; GRINDLE, 1990). Tais etapas

correspondem a uma sequência de elementos do processo político-administrativo e podem ser investigadas no que diz respeito às constelações de poder, às redes políticas e sociais e às práticas político-administrativas que se encontram tipicamente em cada fase. (FREY, 2009)

Nesta pesquisa, enfatiza-se a etapa de implementação de políticas públicas, fase em que as escolhas e os planos provenientes do processo de formulação, se convertem em ações e resultados (FREY, 2009; SECHI, 2010; THOMAS; GRINDLE, 1990). A análise do processo de implementação vai além da aplicação de técnicas para a avaliação do desempenho da política pública; ela busca orientar a concretização bem-sucedida dos objetivos dos programas durante sua execução, a fim de alcançar uma implementação efetiva e condizente com o que foi planejado (LANE, 1983; SABATIER; MAZMANIAN, 1979).

Não é raro, no Brasil, evidenciar divergências entre resultados esperados e efetivos das políticas públicas implementadas. Nesse contexto, a análise da fase de implementação torna-se um importante elemento na promoção do uso 
eficiente dos recursos públicos, pois além de permitir a identificação de falhas e obstáculos limitantes para a execução de projetos, possibilita também "visualizar erros anteriores à tomada de decisão, a fim de detectar problemas mal formulados, objetivos mal traçados, otimismos exagerados” (SECCHI, 2013, p. 45). Além disso, pelo seu potencial de gerar informações que ajudem nas decisões de reestruturação e/ou elaboração de novas políticas, a fase de implementação é vista como uma etapa crucial para sua elaboração (LANE, 2000).

Entende-se que, no processo de análise da implementação, é preciso considerar, principalmente, as pessoas e organizações envolvidas (que, além de assumirem diferentes competências, apresentam interesses e comportamentos variados), bem como suas relações diretas e indiretas e os recursos políticos, financeiros, humanos, informativos e materiais (LANE, 1983; SABATIER; MAZMANIAN, 1979; SECCHI, 2013).

As políticas públicas sofrem influência de vários atores durante todo o seu ciclo. Por isso, "o desenho estratégico das políticas deve incluir a identificação dos atores que dão sustentação à política e mecanismos de concertação e negociação entre tais atores” (SILVA; DE MELO, 2000, p. 13), considerando-se como atores todos os indivíduos, grupos ou organizações que exercem algum papel no cenário político, podendo ser classificados como: governamentais (políticos, designados politicamente, burocratas, juízes, dentre outros) e/ou não governamentais, como grupos de interesses, partidos políticos, meios de comunicação, destinatários das políticas públicas, organizações do terceiro setor e outros stakeholders (SECCHI, 2013).

Em todo ciclo político, os atores proeminentes são os que, direta ou indiretamente, influenciam os processos e/ou os resultados envolvidos na política pública. Cada um, a depender de sua posição, pode influenciar desde a opinião pública até a forma da distribuição dos recursos disponíveis para o programa ou política (ROMAN, 2017; SECCHI, 2013). 
Dentre as diversas organizações envolvidas nos ciclos de política pública, ressalta-se nesta pesquisa o importante papel exercido pelas universidades públicas brasileiras nos processos de elaboração, implantação e, consequentemente, nos resultados, uma vez que são produtoras de conhecimento técnico e científico (GUNASEKARA, 2006; SERRANO, 2013). Ressalta-se, nesse contexto, o potencial da extensão universitária, que consiste no "processo educativo, cultural e científico que articula o Ensino e a Pesquisa de forma indissociável e viabiliza a relação transformadora entre Universidade e Sociedade” (FORPROEXT, 2001, p. 5).

As universidades assumem "o importante papel de sintetizar os saberes que relacionam o universal (conhecimentos científicos e tecnológicos) com a diversidade do particular (o ambiente sociocultural)” (KAWASAKI, 1997, p. 251). Segundo Corrêa (2003), toda e qualquer ação de extensão universitária deve ser orientada por diretrizes que podem ser agrupadas em quatro dimensões: "a relação social de impacto, a bilateralidade, a interdisciplinaridade e a indissociabilidade do ensino, da pesquisa e da extensão" (CORRÊA, 2003, p. 13).

As relações entre as universidades e os outros setores da sociedade tendem a transformar e melhorar a qualidade de vida dos cidadãos (BRENNAN; KING; LEBEAU, 2004; CORRÊA, 2003). Na universidade, são oferecidas as oportunidades de estudar os fatos e princípios que envolveram a sociedade no passado, preparando-a para o presente e para o futuro (HARKAVY, 2006).

A atuação efetivamente transformadora de uma universidade, por sua vez, "demanda que uma abordagem dos problemas da comunidade seja feita segundo uma visão abrangente da realidade social na qual está inserida, relacionando a particularidade desses problemas à complexidade das relações socioeconômicas e políticas” (CORRÊA, 2003, p. 14). Nesse contexto, “a extensão universitária deve superar a cultura de projetos pontuais e desarticulados, não vinculados a programas, e de pequena contribuição conceitual e/ou de pouca contribuição à transformação e à inclusão social” (CORRÊA, 2003, p. 14). 
A importância do papel das universidades no contexto da inovação, do desenvolvimento regional, nas esferas política, econômica, cultural, da transferência de conhecimento e de tecnologia, ou mesmo de atração e retenção de recursos humanos e financeiros para os territórios tem sido discutida pela literatura (GERRITSEN, 2016; GUNASEKARA, 2006; RUAN; SAAD; KUMAR, 2014; SCHWARTZMAN, 2003; WOLFE, 2005). Brennan, King e Lebeau (2004, p. 26) ressaltam que as transformações advindas das universidades poderiam ser consideradas com base nas seguintes dimensões: econômica - por meio da formação de capital humano; política - criação e manutenção de instituições estatais e civis; seleção e socialização das elites políticas e sociais; estrutura social - a base da estratificação social, a amplitude e os mecanismos de mobilidade para diferentes grupos; cultural - com a produção e difusão do pensamento, exercendo influência e fundamentando a crítica das demais dimensões.

Assim, a universidade tende a contribuir no desenvolvimento regional e nacional, ao participar significativamente em processos de construção das políticas públicas, do sistema social, dos direitos humanos, da democracia, da vida e da paz, ao inserir-se no seu tempo e espaço, com base na afirmação da indissociabilidade entre a extensão universitária, o ensino e a pesquisa. Não obstante, entende-se que a ação da universidade não deve subjugar a ação, nem as responsabilidades dos policymakers, mas sim gerar parcerias, no que lhe couber, nos diferentes momentos do ciclo político (BRENNAN; KING; LEBEAU, 2004; CORRÊA, 2003).

Quando se discute o papel das universidades no contexto da cultura, emerge uma série de implicações sobre seus impactos, que variam muito, resultando em diferentes combinações entre papéis tradicionais, como o ensino e a pesquisa, e papéis mais recentes, como o da extensão. Muitos dos impactos das universidades são mensuráveis, tais como o número de formandos nas áreas relacionadas às artes ou os níveis de frequência em eventos culturais. Já outros impactos, como os processos mais amplos de inovação cultural e a 
participação nas políticas de cultura, são mais difíceis de quantificar. Isso se dá, principalmente, porque as relações da universidade com as comunidades são altamente específicas para cada localidade, sendo determinadas por fatores como: a história institucional, os professores, os cursos e seus respectivos alunos, bem como sua localização física (CHATTERTON, 2000, p. 169).

Ao longo dos séculos, as universidades têm sido importantes centros de apoio, produção e preservação cultural, recolhendo e abrigando obras de arte, galerias e museus. Atualmente ampliam seu papel como agentes culturais, ao hospedarem centros de convenções e de artes cênicas, cursos voltados para as diversas artes, bem como ao desenvolverem pesquisas e outros trabalhos acadêmicos sobre artes e atividades culturais (GILMORE; COMUNIAN, 2016). Ademais, o papel da universidade não se limita a desenvolver capacidades, habilidades e infraestrutura para artistas e produtores culturais, mas inclui também a criação de mecanismos para transferir esse conhecimento e arcabouço cultural para a sociedade, em suas diferentes escalas geográficas - local e global (CHATTERTON, 2000).

\section{Procedimentos metodológicos}

Esta pesquisa ${ }^{6}$ caracteriza-se predominantemente como uma pesquisa qualitativa, dada a natureza complexa do objeto de estudo, o que demanda uma análise de cunho interpretativo. Para a sua efetivação, optou-se pela realização de estudos de caso em perspectiva comparada, técnica amplamente usada nas ciências sociais, tanto para eventos singulares, quanto para estudos de grande abrangência (SCHNEIDER; SCHIMITT, 1998). Por meio desta perspectiva, é possível "descobrir regularidades, perceber deslocamentos e transformações, construir modelos e tipologias, identificando continuidades e descontinuidades, semelhanças e diferenças, e explicitando as determinações mais gerais que regem os fenômenos sociais” (SCHNEIDER; SCHIMITT, 1998, p. 49).

\footnotetext{
6 Esta pesquisa foi realizada de acordo com as normas estabelecidas pelo Comitê de Ética em Pesquisa, que envolve seres vivos no campo das ciências sociais, conforme autorização institucional (CEP 713581) obtida via Plataforma Brasil do Conselho Nacional de Saúde.
} 
Como unidades de análise, foram pesquisados quatro municípios do estado de Minas Gerais, escolhidos por meio de critérios simples de seleção, que levaram em conta suas diferenças e similaridades. Considerando as características similares, foram escolhidos municípios desse estado com 50 a 100 mil habitantes, que assinaram o termo de adesão ao Sistema Nacional de Cultura até o ano de 2013. Quanto às diferenças, escolheu-se dois municípios que possuem universidade pública e dois que não possuem, como exposto na Tabela 1.

Tabela 1 - Dados dos municípios estudados.

\begin{tabular}{|l|l|l|l|}
\hline \multicolumn{1}{|c|}{ Município } & $\begin{array}{c}\text { Número de habitantes } \\
\text { Censo 2010 (IBGE) }\end{array}$ & Ano de adesão ao SNC & Universidade pública \\
\hline Viçosa & 72.220 & 2012 & Sim \\
\hline Ouro Preto & 70.281 & 2012 & Sim \\
\hline Cataguases & 69.757 & 2013 & Não \\
\hline Ponte Nova & 57.390 & 2013 & Não \\
\hline
\end{tabular}

Fonte: Elaborado pelos autores com base nos dados da pesquisa.

Minas Gerais é o estado que possui o maior número de municípios no Brasil (853) e, por sua vez, o que apresenta maior número de cidades incorporadas ao Sistema Nacional de Cultura, sendo 250 os municípios (23,9\%) assinantes do acordo de cooperação e inserção. Além disso, Minas Gerais possui 13 universidades públicas, sendo 11 federais e 2 estaduais, sediadas, em sua maioria, em municípios com população acima de 50 mil habitantes.

O universo deste estudo compreende os atores envolvidos no processo de implantação do SMC de seus respectivos municípios. Em cada local estudado, foram entrevistadas duas pessoas, sendo um membro do poder público e um representante da sociedade civil. Como membro do poder público, escolheu-se o secretário municipal de Cultura em exercício. Quando esse, por algum motivo, não pôde conceder a entrevista, foi enviado um representante. Quanto ao representante da sociedade civil, foi escolhido aleatoriamente pela consulta às listas de contatos dos membros dos Conselhos Municipais de Política 
Cultural (CMPC) de cada município. Contudo, alguns se sentiram inseguros para dar entrevista e indicaram outros membros, que julgaram serem mais atuantes nos conselhos.

Foram realizadas entrevistas em profundidade com roteiro semiestruturado, no período de maio a agosto de 2016 (ano base utilizado para a coleta e construção dos dados apresentados), que contribuíram para analisar as funções e as relações dos diferentes atores encarregados de liderar o processo de implementação dos Sistemas Mineiros de Cultura em questão, com destaque para o engajamento das universidades nesse contexto. Para fins desta pesquisa, ressalta-se que o engajamento foi entendido como o papel esperado e as principais ações e práticas da universidade pública no que tange ao processo de implantação do SMC.

Durante a pesquisa, também foram consultados documentos públicos e privados, obtidos em websites e in loco, para confirmarem ou refutarem os dados fornecidos pelos entrevistados (validação), assim como para identificar dados que oferecessem maior suporte para o entendimento do processo de construção dos SMCs. Entende-se que "estudos baseados em documentos como material primordial, sejam revisões bibliográficas, sejam pesquisas historiográficas, extraem deles toda a análise, organizando-os e interpretando-os segundo os objetivos da investigação proposta” (PIMENTEL, 2001, p. 180). Assim, as fontes também auxiliaram no entendimento e na análise dos componentes da estrutura dos SMCs nos municípios estudados.

Para tratamento dos dados captados das fontes e instrumentos, foi utilizado o método de análise de conteúdo (AC) que, segundo Bardin (2016, p. 44), “aparece como um conjunto de técnicas de análise das comunicações, que utiliza procedimentos sistemáticos e objetivos de descrição do conteúdo das mensagens”. Optou-se por empregar a técnica de categorização prévia, sendo 
as categorias construídas por meio da "implementação per se, seus elementos, seus contornos, suas relações, seu desenvolvimento temporal, tendo um objetivo mais descritivo que prescritivo" (SECCHI, 2013, p. 46).

\section{Carências dos sistemas municipais de cultura e um potencial inexplorado das universidades públicas}

O SNC é um instrumento de gestão compartilhada entre os entes federados e a sociedade civil, para a elaboração e execução de políticas públicas de cultura. Tem como órgão gestor e coordenador, em âmbito nacional, a Secretaria Especial da Cultura, antigo Ministério da Cultura (MinC), extinto no ano de 2019. As secretarias estaduais/distrital e municipais de cultura ou equivalentes em seu âmbito de atuação configuram, por sua vez, a direção em cada esfera de governo (BRASIL, 2013).

O SNC apresenta como estrutura formal, nas suas respectivas esferas da federação: (i) uma coordenação (regida pelo órgão gestor da cultura); (ii) instâncias de articulação, pactuação e deliberação (formadas por conselho de política cultural, conferência de cultura, comissão intergestores); (iii) instrumentos de gestão (plano de cultura, sistema de financiamento da cultura, sistema de informações e indicadores culturais, programa de formação na área da cultura e sistemas setoriais de cultura) (BRASIL, 2013).

Destes componentes, alguns elementos estruturais são obrigatórios e outros opcionais, a depender da esfera governamental. Embora não sejam obrigatórios, ressalta-se a importância de que os estados e municípios que apresentam condições instalem todos os componentes dos sistemas, simplesmente por serem úteis à democrática gestão pública da cultura (CUNHA FILHO, 2010). Cada um desses componentes foi descrito de maneira individual e analisado de forma comparada, apresentando as peculiaridades dos municípios estu- 
dados. Ao mesmo tempo, foram feitas as observações sobre a atuação das universidades em cada um deles, quando cabíveis, assim como no sistema municipal de forma geral.

Embora as conferências estaduais e municipais tenham antecedido as conferências nacionais, nota-se que, no processo de construção da política pública, as diretrizes do SNC foram definidas pelas instâncias superiores - Conselho Nacional de Cultura e o extinto Ministério da Cultura. Em uma tipologia simplificada, é possível caracterizar o SNC como uma política do tipo top down (de cima para baixo), cuja agenda e formulação foram decididas e elaboradas em instâncias superiores do governo federal, havendo pouca participação dos municípios. Por fim, a estes coube apenas a adoção e implementação da política. Não obstante, a partir do momento da adesão dos municípios ao SNC, os SMCs constituíram-se como os principais articuladores das políticas públicas de cultura no âmbito municipal.

Vitória e Emmendoerfer (2015) mencionam que expressiva parte dos SMCs foi constituída por isomorfismos miméticos, o que pode ser observado também nos casos estudados. Com exceção de Ouro Preto, os textos que criam as leis dos municípios de Viçosa, Cataguases e Ponte Nova foram elaborados com base em um modelo disponibilizado na internet pelo MinC.

A respeito dos textos das leis, nota-se que poucas adaptações foram feitas a fim de adequar cada documento à realidade local. Isso fez com que, nas estruturas dos sistemas, alguns itens fossem criados pela lei, mas não tivessem valor e/ou existência real. Além disso, em alguns casos, existem outros sistemas setoriais que não foram incluídos como parte do SMC, apesar de existirem no município. Tal fato pode demonstrar um desconhecimento desses sistemas setoriais ou a falta de integração do sistema municipal como um todo, por parte dos órgãos gestores e de apoio. A estrutura do sistema de cultura de cada um dos municípios pode ser observada na Tabela 2: 
Tabela 2 - Estrutura dos Sistemas Municipais de Cultura.

\begin{tabular}{|c|c|c|c|c|}
\hline $\begin{array}{c}\text { Município } \\
\text { Componentes }\end{array}$ & Viçosa & Ouro Preto & Cataguases & Ponte Nova \\
\hline $\begin{array}{l}\text { Lei de } \\
\text { institucionalização } \\
\text { do SMC }\end{array}$ & Possui & Não Possui & Possui & Possui \\
\hline Coordenação & $\begin{array}{l}\text { Secretaria } \\
\text { de Cultura e } \\
\text { Patrimônio }\end{array}$ & $\begin{array}{l}\text { Secretaria } \\
\text { de Cultura e } \\
\text { Patrimônio }\end{array}$ & $\begin{array}{l}\text { Secretaria de } \\
\text { Cultura e Turismo }\end{array}$ & $\begin{array}{l}\text { Secretaria de } \\
\text { Cultura e Turismo }\end{array}$ \\
\hline $\begin{array}{l}\text { Conselho Municipal } \\
\text { de Política Cultural }\end{array}$ & $\begin{array}{l}\text { Criado pela lei do } \\
\text { SMC, mas inativo } \\
\text { desde } 2015\end{array}$ & $\begin{array}{l}\text { Criado por lei } \\
\text { própria, mas } \\
\text { inativo por um } \\
\text { ano (2015 a 2016) }\end{array}$ & $\begin{array}{l}\text { Criado pela } \\
\text { lei do SMC e } \\
\text { funcionando }\end{array}$ & $\begin{array}{l}\text { Criado pela } \\
\text { lei do SMC e } \\
\text { funcionando }\end{array}$ \\
\hline Conferência & Intermunicipal & Municipal & Municipal & Intermunicipal \\
\hline $\begin{array}{l}\text { Plano Municipal } \\
\text { de Cultura }\end{array}$ & Em elaboração & Em elaboração & Pronto & Em elaboração \\
\hline $\begin{array}{l}\text { Sistema de } \\
\text { Financiamento }\end{array}$ & $\begin{array}{l}\text { Criado pela lei } \\
\text { do SMC, mas näo } \\
\text { implementado }\end{array}$ & $\begin{array}{l}\text { Criado por lei } \\
\text { própria, mas nāo } \\
\text { implementado }\end{array}$ & $\begin{array}{l}\text { Criado pela lei } \\
\text { do SMC. Em } \\
\text { funcionamento }\end{array}$ & $\begin{array}{l}\text { Criado pela lei } \\
\text { do SMC. Em } \\
\text { funcionamento }\end{array}$ \\
\hline $\begin{array}{l}\text { Sistema de } \\
\text { Informaçōes e } \\
\text { Indicadores Culturais }\end{array}$ & $\begin{array}{l}\text { Criado pela lei } \\
\text { do SMC, mas não } \\
\text { praticado }\end{array}$ & Inexistente & $\begin{array}{l}\text { Criado pela lei } \\
\text { do SMC, mas não } \\
\text { praticado }\end{array}$ & $\begin{array}{l}\text { Criado pela lei } \\
\text { do SMC. Em } \\
\text { funcionamento }\end{array}$ \\
\hline Sistemas Setoriais & $\begin{array}{l}\text { Existentes, mas } \\
\text { nem todos estão } \\
\text { reconhecidos na } \\
\text { lei do SMC }\end{array}$ & $\begin{array}{l}\text { Existentes, } \\
\text { mas não são } \\
\text { reconhecidos } \\
\text { e estruturados } \\
\text { por lei }\end{array}$ & $\begin{array}{l}\text { Existentes, mas } \\
\text { nem todos estão } \\
\text { reconhecidos na } \\
\text { lei do SMC }\end{array}$ & $\begin{array}{l}\text { Existentes, mas } \\
\text { nenhum está } \\
\text { reconhecido na } \\
\text { lei do SMC }\end{array}$ \\
\hline
\end{tabular}

Fonte: Elaborado pelos autores com base nos dados da pesquisa.

A priori, como critério de adesão dos municípios ao SNC, exigia-se dos mesmos a estrutura de no mínimo: um órgão gestor, que seria o coordenador da cultura local; um conselho municipal de política cultural e um sistema de financiamento à cultura ou fundo municipal de cultura. Após assinarem o termo de adesão, os municípios deveriam criar uma lei municipal que instituía o seu próprio SMC. Destaca-se neste estudo que, apesar de Ouro Preto ser, dentre os municípios analisados, um dos primeiros a aderir ao SNC, esse município ainda não apresenta uma lei própria, que crie o sistema municipal de cultura, mesmo estando inserido no SNC, por atender aos quesitos mínimos de assinatura da adesão. 
Em nenhum dos casos estudados existe uma secretaria de cultura exclusivamente, sendo que essa divide suas funções com outras áreas. Assim, os órgãos responsáveis pela coordenação do SMC nos respectivos municípios são: Viçosa, Secretaria Municipal de Cultura e Patrimônio; Ouro Preto, Secretaria Municipal de Cultura e Patrimônio; Cataguases, Secretaria de Cultura e Turismo; Ponte Nova, Secretaria de Cultura e Turismo.

Os conselhos gestores de políticas públicas são canais de participação, que permitem à sociedade exercer sua cidadania de forma ativa. Não obstante, os pontos de maior complexidade de todos os sistemas estudados podem ser vistos nos conselhos municipais de política cultural, sendo estes sempre apontados, em maior ou menor grau, por todos os entrevistados, como um dos elementos essenciais para o bom funcionamento do sistema, ao mesmo tempo em que se apresenta como fonte de grande parte dos seus problemas.

O Conselho Municipal de Viçosa foi desativado em 2015, ano em que o primeiro mandato dos conselheiros venceu, não tendo sido convocadas novas eleições, devido à falta de participação dos conselheiros nas reuniões e ao fato de o então secretário de Cultura, sendo presidente do conselho, não ter convocado novas eleições. O mesmo caso aconteceu em Ouro Preto, contudo, em maio de 2016, a secretária de Cultura em exercício convocou uma nova eleição, na qual foi votada uma equipe de conselheiros, representantes da sociedade civil, permanecendo as mesmas cadeiras do poder público. Em Cataguases e Ponte Nova, por sua vez, como o primeiro mandato dos conselheiros começou em 2014, sua vigência não havia vencido até o final da coleta de dados. Mesmo assim, os entrevistados desses dois municípios também se queixam da pouca presença dos conselheiros.

Tanto em Viçosa, que possui a Universidade Federal de Viçosa (UFV), quanto em Ouro Preto, sede da Universidade Federal de Ouro Preto (UFOP), desde a criação dos conselhos, uma das cadeiras foi destinada a representantes dessas instituições, pois acredita-se que elas exercem grande influência no desenvol- 
vimento local, não somente nos âmbitos econômico, técnico e científico, mas também cultural. Todavia, em ambos os casos, uma das representações menos presentes no conselho é a da universidade. Segundo os entrevistados, a falta desses integrantes prejudica o conselho não apenas pela falta de quórum nas reuniões, mas também por este deixar de ter a colaboração da universidade em todo o suporte técnico e científico que ela poderia oferecer ao conselho e ao SMC como um todo.

O conselho de Viçosa é composto por 20 representantes, Cataguases, por 22 e Ponte Nova, também por 22, dos quais a metade são representantes de órgãos públicos que apresentam relações diretas com o setor cultural local, sendo a outra metade de representantes das diferentes classes artísticas e culturais do município (sociedade civil). A diferença do conselho de Ouro Preto é que ele apresenta apenas dez representantes, sendo as cinco cadeiras destinadas à sociedade civil, as quais são ocupadas por instituições culturais escolhidas por meio de eleição e não por diferentes classes culturais e artísticas, como observado nos outros municípios.

Os conselhos, junto com as Conferências Municipais de Cultura, são as instâncias de articulação, pactuação e deliberação dos SMCs. Em Ouro Preto e Cataguases, houve conferências municipais para levantamento das demandas que seriam apresentadas por seus delegados nas conferências estaduais e federais. Já em Viçosa e Ponte Nova, não houve nenhuma conferência de cultura exclusiva, mas sim conferências intermunicipais, com participação de delegados dos municípios vizinhos eleitos para representar a região nas demais conferências - estadual e nacional. A participação das universidades de Ouro Preto e de Viçosa se deu por meio da concessão de seus espaços, sendo que, em Ouro Preto, aconteceu nas dependências da Escola de Farmácia, enquanto em Viçosa ocorreu dentro do campus universitário.

Por meio do Sistema Municipal de Informação e Indicadores Culturais (SMIIC), os gestores poderiam levantar todos os indicadores culturais do município - 
dados dos artistas, produtores, grupos de cultura popular, patrimônio material e imaterial, eventos, equipamentos culturais, órgãos públicos e privados e movimentos sociais -, sendo possível planejar e executar com maior precisão programas e projetos culturais. Contudo, o único município que declarou possuir um SMIIC funcionando foi Ponte Nova, o qual não está descrito na lei municipal que criou o SMC. Por outro lado, Viçosa apresenta o SMIIC descrito na lei, mas que não funciona de fato.

Segundo os entrevistados, a Secretaria de Cultura de Ouro Preto está levantando os dados do município, no entanto não de maneira sistematizada. Cataguases não possui um SMIIC formal, mas atribuiu a rapidez na elaboração do seu plano a muitos trabalhos anteriores, feitos por pesquisadores e produtores locais, que vêm contando a história cultural do município. Isso facilitou quando foi preciso organizar as informações municipais.

Nos casos de Viçosa e Ouro Preto, poderia ter sido verificada a existência de dados já sistematizados, visto que em ambas as universidades existem diversos trabalhos acadêmicos que discutem a realidade local. A sistematização dos dados culturais também poderia ser feita por meio de parcerias do poder público com as diversas unidades das universidades, incluindo tanto aquelas que são ligadas à cultura - como os cursos de artes, história, arquitetura, dentre outros - quanto os departamentos das áreas de gestão e de tecnologias de informação.

Os Sistemas Setoriais de Cultura (SSC) existem em todos os municípios estudados, mas apenas em Viçosa e Cataguases estão previstos pelas leis dos SMC. Não obstante, em nenhum dos quatro municípios os SMIICs estão de fato planejados e atuando como parte do SMC. Isso poderia ser diferente, principalmente em Viçosa e Ouro Preto, visto que as próprias universidades podem ser consideradas como sistemas setoriais de cultura dos seus respectivos municípios, além disso, os cursos de artes, arquitetura e história, presentes nessas duas universidades formam outros subsistemas culturais. 
Em outra dimensão, as bibliotecas das universidades poderiam se integrar com as demais bibliotecas municipais, formando um sistema municipal de bibliotecas, o que poderia ser replicado também em relação aos museus, centros de arte e cultura, ou mesmo entre os estudantes de artes. Todos esses subsistemas existem e estão ligados, de alguma forma, às universidades, existindo, muitas vezes, apenas por causa delas. Portanto, eles poderiam trabalhar de forma sistêmica com o município onde estão inseridos, mas ainda falta organizá-los e vinculá-los ao SMC.

Estes elementos indicam que o potencial de contribuição das universidades em relação ao sistema municipal de cultura não tem sido explorado pelas instituições analisadas no presente trabalho. Tal resultado aponta para o desarranjo institucional presente nos SMCs estudados que, por sua vez, apresentam uma baixa expressividade universitária, aproximando os desempenhos dos municípios que possuem universidades e os que não possuem, em termos de composição dos Sistemas Municipais de Cultura.

Como era de caráter obrigatório para a adesão ao SNC, todas as quatro cidades criaram o seu Sistema Municipal de Financiamento à Cultura (SMFC), especificamente o Fundo Municipal de Cultura. Entretanto, em Ouro Preto e Viçosa, esse fundo nunca serviu, efetivamente, para financiar projetos vinculados ao sistema e, por falta de documentação, a prefeitura destinou o dinheiro do fundo a outros setores do município.

Nesse mesmo quesito, Cataguases e Ponte Nova, desde que foram criados os fundos (cada qual com valor correspondente à arrecadação municipal), estão financiando projetos por meio de editais lançados anualmente. Além do fundo, os dois municípios conseguiram que a câmara votasse um orçamento anual fixo destinado ao setor da cultura. Ainda como parte do SMFC, Cataguases tem também a lei "Ascânio Lopes”, que prevê que parte dos projetos culturais do município sejam financiados por meio de renúncia fiscal, pela qual a prefeitura deixaria de receber parcela dos impostos de contribuintes dispostos a financiar a cultura local. 
Incluídos nos SMFCs, os fundos aplicam recursos, quase sempre de origem orçamentária, diretamente na execução ou no apoio a programas, projetos e ações culturais, realizados pelo poder público e pela sociedade. No Sistema Nacional de Cultura, os fundos constituem-se como principal mecanismo de financiamento, funcionando em regime de colaboração e cofinanciamento entre os entes federados.

A possibilidade de aumentar os recursos do município para a cultura, que seriam repassados fundo a fundo, foi o principal motivo alegado por todos os entrevistados, principalmente os secretários de cultura, para que os municípios aderissem ao SNC. O que foi também o principal motivo de frustrações, pois, até a conclusão das entrevistas, não tinha havido repasse, nem pela União, nem pelo governo estadual, via fundo, como previsto na formulação da política pública.

O Plano de Cultura estabelece estratégias para que, a médio e longo prazo, os municípios possam concluir as metas de implementação de seu sistema. O plano deve ser elaborado pelo órgão gestor, com a colaboração do Conselho Municipal de Política Cultural, a quem cabe aprová-lo. O plano e o sistema deveriam andar juntos desde o começo, sendo o primeiro orientador do segundo. Entretanto, o único município que apresenta um plano é Cataguases, que o aprovou junto ao conselho e à câmara municipal, no final de 2015.

Os demais municípios alegaram que estão em fase de elaboração, mas falta a participação de grande parte dos conselheiros e de demais pessoas tecnicamente capacitadas para a sua elaboração. A necessidade de capacitação e assistência técnica para a elaboração dos planos municipais de cultura revela abertura para a atuação efetiva das universidades públicas, por meio da intervenção dos conselheiros que as representam. Todavia, foi observado que em Viçosa e em Ouro Preto não existiu essa iniciativa, nem por parte dos demais conselheiros ou do órgão gestor, nem por parte das universidades. 
Durante as entrevistas, quando questionados se houve participação efetiva de alguma universidade e/ou instituição de ensino superior no SMC, todos os entrevistados citaram a participação apenas da Universidade Federal da Bahia (UFBA), pois esta havia oferecido um curso online para capacitação de gestores e conselheiros de cultura. Esse curso, intitulado "Formação para a Elaboração de Planos Municipais de Cultura”, foi um projeto promovido pelo MinC por intermédio da Secretaria de Articulação Institucional (SAI), em parceria com a Escola de Administração da UFBA. Seu principal objetivo, declarado, foi disseminar conhecimento técnico em planejamento cultural e ampliar a capacidade de elaboração de planos de cultura nos municípios brasileiros que aderiram ao Sistema Nacional de Cultura. Tal iniciativa resultou na produção de um guia (BRASIL, 2017), que pode servir de ponto de partida para os municípios desenvolverem planos públicos de cultura e iniciarem a mobilização para a constituição de SMCs.

A existência desse treinamento indica mais uma possibilidade de intervenção das universidades nos sistemas municipais de cultura. Ele poderia ter sido aplicado em cada região separadamente, de forma participativa junto às universidades espalhadas pelo Brasil, em especial as públicas. Neste caso, as universidades de Ouro Preto e de Viçosa poderiam ter atendido não somente aos respectivos municípios nos quais estão inseridas, mas também a toda a região, o que englobaria as outras duas cidades estudadas, pois Cataguases, que é a mais distante, situa-se a pouco mais de 100 km do município de Viçosa.

Num esforço de aprofundar o conhecimento a respeito do papel das universidades na implementação da política pública em análise, procurou-se também verificar a possível atuação de outras instituições de ensino superior no SNC, para além dos casos selecionados. Assim, verificou-se que, em abril de 2013, foi realizado o "I Seminário Cultura e Universidade - Bases para uma política nacional de cultura para as Instituições de Ensino Superior”, pelo extinto Ministério da Cultura, em parceria com a Universidade Federal da Bahia (UFBA) e o Fórum de Pró-Reitores de Extensão. 
Durante três dias, foram reunidas pessoas de setores relacionados ao campo da cultura e da educação, com o objetivo de sensibilizar, mobilizar e articular instituições públicas de ensino superior, além de dialogar sobre ações que promovessem o desenvolvimento da cultura, envolvendo a ampliação de programas e cursos voltados para formação, pesquisa e extensão em arte, cultura, comunicação, gestão pública, técnicas e processos relacionados aos setores criativos. 0 diálogo foi feito por meio de palestras, mesas de discussão e grupos temáticos.

Apesar de ter sido incluída uma mesa temática intitulada "A formação de gestores culturais e o Sistema Nacional de Cultura”, segundo o documento que divulga os resultados do seminário (BRASIL, 2013), foi discutido apenas o papel da universidade na formação dos artistas, gestores e produtores culturais, não sendo abordado seu papel em relação ao SNC ou à formulação e implementação de políticas públicas de cultura. Em se tratando das universidades estudadas, não foi possível identificar, nem nas entrevistas nem em outros documentos, se elas participaram dos seminários.

A pesquisa permitiu observar uma centralização de funções na UFBA, referente às ações universitárias na política do SNC e dos demais sistemas que 0 integram. Contudo, não se sabe se tal configuração é proposital ou reflete apenas o engajamento dessa instituição. Reforça-se, porém, com esta evidência, o potencial da atuação das universidades estudadas na construção e aprimoramento dos Sistemas Municipais de Cultura das regiões em que estão inseridas, seja pela orientação, pesquisa, capacitação dos membros dos conselhos ou por intermédio de outras atividades que atendam às expressivas carências evidenciadas na análise dessa política pública.

\section{Considerações finais}

O papel das universidades diante das políticas públicas de cultura vem sendo repensado, tanto no meio acadêmico como no âmbito da administração pú- 
blica, junto aos órgãos competentes do setor. Contudo, muito ainda tem a ser feito, visto que as ações culturais da universidade ainda estão voltadas apenas para a comunidade acadêmica.

Embora o papel das universidades possa ser distinto, dependendo da finalidade socioeconômica e da organização jurídica de cada uma, esperava-se que nos municípios estudados que possuem universidades públicas, os SMCs dessas localidades fossem mais desenvolvidos que os demais. Das questões levantadas nesta pesquisa, evidencia-se o potencial de contribuição das instituições públicas de ensino superior para a consolidação dos Sistemas Municipais de Cultura, seja pela capacitação, orientação ou análises do contexto local. Elementos esses condizentes com a missão universitária de proporcionar ensino, pesquisa e extensão, para atender às demandas da sociedade.

O pressuposto levantado, porém, não foi confirmado. Pelo contrário, a pesquisa evidenciou que as universidades, ao não assumirem um engajamento efetivo junto ao SMC, estão aquém do cumprimento de seu papel participativo de transferência de conhecimento e de sua responsabilidade como entidades culturais, no contexto das demandas das políticas públicas. O fato de haver uma universidade pública no município demonstrou ainda baixa contribuição - ou nula - para o desenvolvimento do SMC. Verificou-se que o bom funcionamento do SMC depende da atuação da secretaria de cultura local e da formação e capacidade técnica do gestor, independentemente de haver uma universidade pública no município. Ressalta-se que tal constatação, é relacionada estritamente ao SMC e ao papel institucional da universidade, desconsiderando ações endógenas e iniciativas individuais ou coletivas relacionadas à cultura, empreendidas por técnicos, docentes e discentes, dentro e fora do campus universitário.

Diante dos problemas evidenciados no processo de implantação dos Sistemas Municipais de Cultura (baixa participação social, desorganização institucional, falta de capacitação), a participação ativa das universidades poderia oferecer estruturas favoráveis ao desenvolvimento dos sistemas e, por fim, para a efeti- 
vidade da política pública. Observou-se que é desejada, por parte dos entrevistados, maior presença e engajamento das universidades junto aos SMCs.

Em relação à questão da presença das universidades, é preciso refletir sobre o processo de indicação de seus representantes institucionais. Faz-se necessário que haja ampla divulgação nos meios de comunicação interna, para conhecimento da comunidade universitária, dessas vagas de representação, as quais possuem atuação honorífica e voluntária nos SMCs. Tal ação interna pode estimular candidaturas de pessoas competentes e com interesse na questão da cultura, minimizando designações de natureza política e do tipo pro forma, ou seja, apenas para atender à demanda das prefeituras, o que tende a redundar, com o passar do tempo, em baixa participação e envolvimento. Este tipo de situação pode fragilizar a imagem institucional da universidade, devido à baixa atenção que alguns designados demonstram com as demandas externas relacionadas à área da cultura, bem como dos tomadores de decisão nas universidades.

Sobre o engajamento, esperava-se que as universidades cumprissem seu papel de formação, oferecendo capacitação aos gestores e conselheiros, bem como de colaboração (por meio da coprodução de documentos, como planos municipais de cultura autóctones) e de coordenação. Até mesmo, pela utilização da Teoria do Programa, em que é possível a construção de um modelo lógico (VITÓRIA et al., 2020) que favoreça a adesão de municípios ao SNC e/ ou a criação de um SMC em suas respectivas localidades. Tal atuação formativa-colaborativa da universidade, fundamentando-se, a priori, no Plano Nacional de Educação e nas Diretrizes para as Políticas de Extensão da Educação Superior Brasileira (BRASIL, 2018), poderia tornar efetivo seu potencial de transformação social, por meio da promoção do desenvolvimento regional no contexto da cultura.

Assim, os aspectos examinados, somados a pesquisas que possam identificar o modus facendi e avaliar sistematicamente os papéis possíveis de atuação das universidades em SMCs, tornam-se temas relevantes para estudos futuros no 
campo, bem como para o fortalecimento de práticas em defesa da preservação de bens e serviços culturais em níveis local e regional. Tal papel se torna mais proeminente e necessário em tempos de crise e baixa priorização governamental de investimentos em cultura.

Todavia, levando em consideração a perspectiva do ciclo político, apesar da baixa participação nas etapas de formulação e implementação dos SMCs, as universidades podem vir a ser protagonistas das referidas políticas culturais nas diferentes esferas - municipais, estaduais e federal - assumindo suas avaliações, as quais podem ser formativas ou somativas. Este é um ponto de partida importante apresentado como contribuição neste artigo.

Por estar em fase de implementação, a avaliação formativa seria um meio de apoiar e melhorar a gestão, a implementação e o desenvolvimento dos programas. Na fase de implementação, existem muitos aspectos e nuances que podem influenciar o seu processo; uma avaliação formativa poderia corrigir e até alterar alguns fatores que dificultam ou impedem o bom desenvolvimento das políticas culturais. Por sua vez, após a implementação de cada fase prevista pelos planos de cultura, as universidades podem, junto às secretarias de cultura, realizar avaliações somativas para analisar os outputs (produtos) e outcomes (efeitos) dos sistemas e planos municipais de cultura.

\section{Referências}

BARDIN, Laurence. Análise de conteúdo. 5. ed. Lisboa: Edições 70, 2016.

BRASIL. Constituição da República Federativa do Brasil de 1988. Brasília: Casa Civil, 1988. Disponível em: http://www.planalto.gov.br/ccivil_03/constituicao/ constituicaocompilado.htm. Acesso em: 19 set. 2020.

BRASIL. Lei 13.005 de 25 de junho de 2014. Aprova o Plano Nacional de Educação - PNE e dá outras providências. Brasília: Casa Civil, 2014. Disponível em: http://www.planalto.gov.br/ccivil_03/_ato2011-2014/2014/lei/113005.htm. Acesso em: 19 set. 2020. 
BRASIL. Ministério da Cultura. Planos Municipais de Cultura: Guia de Elaboração. Salvador: UFBA, 2017. Disponível em: http://pnc.cultura.gov.br/wp-con tent/uploads/sites/16/2017/06/Planos-Municipais-de-Cultura_Guia-de-Elabo rac\%CC\%A7a\%CC\%83o-UFBA_MinC-FINAL-2.pdf. Acesso em: 19 set. 2020.

BRASIL. Oficina de implementação de Sistemas Estaduais e Municipais de Cultura. Brasília: Ministério da Cultura, 2013. Disponível em: http://portalsnc. cultura.gov.br/wp-content/uploads/sites/32/2018/04/Apostila-Oficina-de-Im plementa\%C3\%A7\%C3\%A3o-dos-Sistemas-de-Cultura.pdf. Acesso em: 19 set. 2020.

BRASIL. Plano Nacional de Cultura. Brasília: Ministério do Turismo/Secretaria Especial de Cultura, 2020a. Disponível em: http://pnc.cultura.gov.br/. Acesso em: 19 set. 2020.

BRASIL. Plano Nacional de Cultura: diretrizes gerais. 2. ed. Brasília: Ministério da Cultura, 2008. Disponível em: http://pnc.cultura.gov.br/wp-content/uploads/ sites/16/2018/05/Plano-Nacional-de-Cultura-Diretrizes.pdf. Acesso em: 19 set. 2020.

BRASIL. Portaria MEC n. 1.350, de 14 de dezembro de 2018. Institui as Diretrizes para as Políticas de Extensão da Educação Superior Brasileira. Brasília: Imprensa Nacional; Ministério da Educação, 2018. Disponível em: http://portal. mec.gov.br/docman/novembro-2018-pdf/102551-pces608-18/file. Acesso em: 19 set. 2020

BRASIL. Sistema Nacional de Cultura. Brasília: Ministério do Turismo/Secretaria Especial da Economia Criativa e Diversidade Cultural, 2020b. Disponível em: http://portalsnc.cultura.gov.br/. Acesso em: 19 set. 2020.

BRENNAN, John; KING, Roger; LEBEAU, Yann. The role of universities in the transformation of societies: Synthesis report. London: Centre for Higher Education Research and Information, Association of Commonwealth Universities, 2004.

CHATTERTON, Paul. The cultural role of universities in the community: revisiting the university - community debate. Environment and Planning A: Economy and Space, [S. l.], v. 32, n. 1, p. 165-181, Jan. 2000. Disponível em: https://doi. org/10.1068\%2Fa3243. Acesso em: 25 jul. 2017. 
CORREAA, Edson José. Extensão universitária, política institucional e inclusão social. Revista Brasileira de Extensão Universitária, Chapecó, v. 1, n. 1, p. 12-15, jul./dez. 2003. Disponível em: https://periodicos.uffs.edu.br/index.php/RBEU/ article/view/864. Acesso em: 25 jul. 2017.

CUNHA FILHO, Francisco Humberto. Federalismo cultural e Sistema Nacional de Cultura: contribuição ao debate. Fortaleza: Edições UFC, 2010.

ETZKOWITZ, Henry; LEYDESDORFF, Loet. The future location of research and technology transfer. The Journal of Technology Transfer, [S. l.], v. 24, n. 2-3, p. 111-123, Aug. 1999. Disponível em: https://doi.org/10.1023/A:1007807302841. Acesso em: 25 jul. 2017.

ETZKOWITZ, Henry et al. The future of the university and the university of the future: evolution of ivory tower to entrepreneurial paradigm. Research Policy, [S. l.], v. 29, n. 2, p. 313-330, Feb. 2000. Disponível em: https://doi.org/10.1016/ S0048-7333(99)00069-4. Acesso em: 25 jul. 2017.

[FORPROEXT] FÓRUM DE PRÓ-REITORES DE EXTENSÃO DAS UNIVERSIDADES PÚBLICAS BRASILEIRAS. Plano Nacional de Extensão Universitária. Edição atualizada. Natal: SeSu-MEC, 2001. Disponível em: https://www.proec.ufg.br/ up/694/o/PNEX.pdf. Acesso em: 25 jul. 2017.

FREY, Klaus. Políticas públicas: um debate conceitual e reflexões referentes à prática da análise de políticas públicas no Brasil. Planejamento e Políticas Públicas, Brasília, n. 21, jun. 2009. Disponível em: https://www.ipea.gov.br/ ppp/index.php/PPP/article/view/89. Acesso em: 14 set. 2020.

GERRITSEN, Rolf et al. A test of the role of universities in regional development: The case of international education students in the Northern Territory. Australasian Journal of Regional Studies, [S. l.], v. 22, n. 1, p. 125-157, 2016. Disponível em: https:// search.informit.com.au/documentSummary; dn=135199283675096;res=IELNZC. Acesso em: 25 jul. 2017.

GILMORE, Abigail; COMUNIAN, Roberta. Beyond the campus: higher education, cultural policy and the creative economy. International Journal of Cultural Policy, [S. l.], v. 22, n. 1, p. 1-9, Nov. 2016. Disponível em: https://doi.org/10.1080/1028663 2.2015.1101089. Acesso em: 25 jul. 2017. 
GUNASEKARA, Chrys. Reframing the role of universities in the development of regional innovation systems. The Journal of Technology Transfer, [S. l.], v. 31, n. 1, p. 101-113, Nov. 2006. Disponível em: https://doi.org/10.1007/s10961-0055016-4. Acesso em: 25 jul. 2017.

HARKAVY, Ira. The role of universities in advancing citizenship and social justice in the 21st century. Education, Citizenship and Social Justice, [S. l.], v. 1, n. 1, p. 5-37, Mar. 2006. Disponível em: https://doi.org/10.1177/1746197906060711. Acesso em: 25 jul. 2017.

KAWASAKI, Clarice Sumi. Universidades públicas e sociedade: uma parceria necessária. Revista da Faculdade de Educação, São Paulo, v. 23, n. 1-2, jan./dez. 1997. Disponível em: http://dx.doi.org/10.1590/S0102-25551997000100013. Acesso em: 25 jul. 2017.

LANE, Jan-Erik. The concept of implementation. Statsvetenskaplig tidskrift, [S. l.], v. 86, n. 1, p. 17-40, 1983. Disponível em: https://journals.lub.lu.se/st/article/down load/3298/2870. Acesso em: 25 abr. 2017.

LANE, Jan-Erik. The public sector: concepts, models and approaches. 3. ed. London: Sage, 2000.

MARTINS, Bárbara Calçado Lopes et al. As mudanças na administração pública e as políticas culturais no Brasil. Revista Interdisciplinar de Gestão Social, [S. l.], v. 5, n. 3, p. 55-83, set./dez. 2016. Disponível em: https://www.researchgate.net/ publication/319074314_As_Mudancas_na_Administracao_Publica_e_as_Politi cas_Culturais_no_Brasil. Acesso em: 25 jul. 2017.

OWEN-SMITH, Jason; POWELL, Walter W. The expanding role of university patenting in the life sciences: assessing the importance of experience and connectivity. Research Policy, [S. l.], v. 32, n. 9, p. 1695-1711, Oct. 2003. Disponível em: https://doi.org/10.1016/S0048-7333(03)00045-3. Acesso em: 25 jul. 2017.

PEIXE, Joao Roberto. Sistemas de cultura. (Coleção Políticas e Gestão Culturais). Salvador: P55 Edições; Secretaria de Cultura do Estado da Bahia, set. 2013. Disponível em: https://repositorio.ufba.br/ri/bitstream/ri/30706/1/gestao-culturalsaladeaula13-RI.pdf. Acesso em: 25 de jul. 2017.

PIMENTEL, Alessandra. O método da análise documental: seu uso numa pesquisa historiográfica. Cadernos de Pesquisa, Rio de Janeiro, n. 114, p. 179-195, 
nov. 2001. Disponível em: http://dx.doi.org/10.1590/S0100-15742001000300008. Acesso em: 25 jul. 2017.

ROMAN, Alexandru V. The determinants of public administrators' participation in policy formulation. The American Review of Public Administration, [S. l.], v. 47, n. 1, p. 102-129, Jan. 2017. Disponível em: https://doi.org/10.1177\%2F0275074015577799. Acesso em: 25 jul. 2017.

RUAN, Ximing; SAAD, Mohammed; KUMAR, Vikas. The transformational role of University in regional innovation system: The case of Zhengzhou University in China. [S. l.: s.n.], Sept. 2014. p. 1-20. Disponível em: http://eprints.uwe.ac.uk/23973. Acesso em: 25 abr. 2017.

SABATIER, Paul; MAZMANIAN, Daniel. The conditions of effective implementation: A guide to accomplishing policy objectives. Policy Analysis, [S. l.], v. 5, n. 4, p. 481-504, 1979.

SCHNEIDER, Sérgio; SCHIMITT, Cláudia Job. O uso do método comparativo nas Ciências Sociais. Cadernos de Sociologia, Porto Alegre, v. 9, p. 49-87, 1998.

SCHWARTZMAN, Simon. Universities and the transformation of society in Brazil. In: SCHWARTZMAN, Simon (Ed.). The role of universities in the transformation of societies (Project Research). London: [S. n.], out. 2003. p. 2-25. Disponível em: http:// www.schwartzman.org.br/simon/pdf/transformation.pdf. Acesso em: 25 abr. 2017.

SECCHI, Leonardo. Políticas públicas: conceitos, esquemas de análise, casos práticos. 2. ed. São Paulo: Cengage Learning, 2013.

SERRANO, Rossana Maria Souto Maior. Conceitos de extensão universitária: um diálogo com Paulo Freire. Grupo de Pesquisa em Extensão Popular, [S. l.], v. 13, n. 8, 2013. Disponível em: https://crystine-tanajura.webnode.com/_files/ 200000021-e6560e752b/conceitos_de_extensao_universitaria.pdf. Acesso em: 25 jul. 2017.

SILVA, Pedro Luiz Barros; DE MELO, Marcus André Barreto. O processo de implementação de políticas públicas no Brasil: características e determinantes da avaliação de programas e projetos. Caderno NEPP/Unicamp, Campinas, n. 48, p. 1-16, out. 2000. Disponível em: https://governancaegestao.files.wor dpress.com/2008/05/teresa-aula_22.pdf. Acesso em: 25 jul. 2017. 
SOUZA, Celina. Políticas públicas: uma revisão da literatura. Sociologias, Porto Alegre, v. 8, n. 16, p. 20-45, jul./dez. 2006. Disponível em: http://dx.doi. org/10.1590/S1517-45222006000200003. Acesso em: 25 jul. 2017.

TEIXEIRA, Elenaldo Celso. O papel das políticas públicas no desenvolvimento local e na transformação da realidade. Salvador: AATR, 2002. Disponível em: http://www.escoladebicicleta.com.br/politicaspublicas.pdf. Acesso em: 14 set. 2020.

THOMAS, John; GRINDLE, Merilee. After the decision: Implementing policy reforms in developing countries. World Development, [S. l.], v. 18, n. 8, p. 11631181, Aug. 1990. Disponível em: https://doi.org/10.1016/0305-750X(90)90096-G. Acesso em: 25 jul. 2017.

VITÓRIA, José Ricardo; EMMENDOERFER, Magnus Luiz. Dificuldades na implementação de um Sistema Municipal de Cultura no Brasil a partir de práticas isomórficas. Políticas Culturais em Revista, [S. l.], v. 8, n. 1, p. 222-238, 2015. Disponível em: https://periodicos.ufba.br/index.php/pculturais/article/ view/13076. Acesso em: 25 jul. 2017.

VITÓRIA, José Ricardo et al. O uso da Teoria do Programa para a construção de um modelo lógico aplicado aos sistemas municipais de cultura no Brasil. TPA Teoria e Prática em Administração, João Pessoa, p. 1-15, jun. 2020. Disponível em: https://periodicos.ufpb.br/index.php/tpa/article/view/49879. Acesso em: 1 set. 2020

WOLFE, David A. The role of universities in regional development and cluster formation. In: JONES, Glen Alan; MCCARNEY, Patricia Louise; SKOLNIK, Michael L. (Eds.). Creating knowledge, strengthening nations: The changing role of higher education. Toronto: University of Toronto Press, 2005. p.167-194.

Recebido em: 20 de fevereiro de 2020 Aprovado em: 22 de setembro de 2020 